\title{
FutureJournal
}

\section{Estratégias de Criação de Valor Compartilhado a Serem Adotadas diante de Cenários Prospectados para a Indústria da Construção Civil no Ceará}

\author{
Mirele Cavalcante da Silva \\ Mestra em Administração de Empresas pela Universidade de Fortaleza, Unifor, Brasil e \\ pela University Deggendorf Institute of Technology, DIT, no curso Strategic and International \\ Management, Alemanha. \\ mirele_cavalcante@hotmail.com

\section{Sergio Henrique Arruda Cavalcante Forte \\ Professor e Coordenador do Programa de Pós Graduação em Administração de Empresas da Universidade de Fortaleza, Unifor, Brasil. \\ sergioforte@unifor.br}

\section{RESUMO}

Devido à repercussão no mundo empresarial do desenvolvimento sustentável, observou-se um setor que impacta diretamente os resultados de negócios e resultados sociais. A indústria da construção civil é um setor que exerce grande influência no crescimento e desenvolvimento de um país, gerando grande impacto econômico, social, cultural e ambiental sendo fundamental para a sustentabilidade do futuro. Diante desse contexto, nesta pesquisa o objetivo geral é identificar como a indústria da construção civil deverá posicionar-se frente ao mercado de criação de valor compartilhado para tornar-se mais competitiva. Esta pesquisa classifica-se como descritiva, com uma fase teórica e outra empírica de natureza qualitativa. Para tanto, foi realizada uma pesquisa bibliográfica e entrevistas exploratórias com cinco especialistas para identificar práticas de criação de valor compartilhado (CSV) da indústria da construção civil no estado do Ceará, conforme modelo proposto por Porter e Kramer. Após isso, foram coletados dados de 22 empresas a fim de identificar o nível de CSV e o perfil das empresas que já se inserem no modelo CSV. A análise dos dados permitiu evidenciar que a indústria da construção civil no estado do Ceará já está inserida no que se refere a CSV, 


\section{FutureJournal}

realizando práticas moderadas e destacando-se com essas práticas dentre as médias empresas. Quanto ao nível de CSV, precisa aprofundar-se especificamente no nível 3 (que permite 0 desenvolvimento de cluster). Por fim, como recomendações para esta indústria, foram listadas 17 estratégias de cunho socialmente responsáveis, sustentáveis e empresariais que buscaram contribuir com ações norteadoras para consolidação de uma construção sustentável.

PALAVRAS-CHAVE: Criação de valor compartilhado. Estratégia. Construção civil. Construção sustentável.

\section{Value Creation Strategies Shared to be taken before Prospected Scenarios for Industry Construction in Ceará}

\section{ABSTRACT}

Due to the impact on the business world of sustainable development, we study a sector that has a direct impact on business results and social outcomes. The construction industry is a sector that has great influence on the growth and development of a country, generating great economic, social, cultural and environmental impact central to the sustainability of the future. In this context, this study has as a general objective to identify how the construction industry must be positioned the shared value creation market to be more competitive. This research is classified as descriptive, with a theoretical phase and an empirical qualitative phase. A literature search and exploratory interviews with five experts to identify practices of creating value were performance on CSV of the construction industry in the state of Ceará according to the model proposed by Porter and Kramer. After that, data from 22 companies were collected in order to identify the level of (CSV) and 


\section{FutureJournal}

FUTURE STUDIES RESEARCH JOURNAL:

TRENDS AND STRATEGIES

the profile of the companies that already fall within the CSV template. Data analysis has highlighted that the construction industry in the state of Ceará is already inserted in relation to CSV, performing moderate practices, especially with the mid-sized firms. As for the CSV level need to deepen specifically at level 3 (allows cluster development). Finally, as recommendations for this industry, 17 socially responsible strategies were listed that seek to contribute to guiding actions to consolidate sustainable construction.

KEY-WORDS: Creating shared value. Strategy. Construction. Sustainable construction. 


\section{INTRODUÇÃO}

O mundo dos negócios passa por mudanças constantes (Porter \& Kramer, 2011). A rapidez das mudanças consequentemente gera incertezas, riscos e cria grandes oportunidades, e a velocidade desses acontecimentos impulsiona as empresas à procura de novas alternativas estratégicas para obter vantagens competitivas (Godet, 2010).

A prospecção de cenários surgiu com a perspectiva de minimizar essa situação, ou seja, reduzir os erros, as incertezas, aumentar as chances de acertar no futuro e dar um melhor direcionamento para as ações e a avaliação das opções estratégicas (Coates, Durance \& Godet, 2010). No entanto, muitas organizações não estão fazendo uso desse recurso e encontram-se muitas vezes despreparadas (Schwartz, 2000; Marcial \& Grumbach, 2006).

Por outro lado, as mudanças ocorridas a partir do século XX tornam cada vez mais difíceis a sobrevivência das organizações no ambiente competitivo (Oliveira \& Forte, 2009). Além disso, percebe-se a nova economia de mercado, que considera fortemente o avanço tecnológico, a revolução verde e a maior esperança pela vida, sendo fatores ambientais e o bem-estar da população temas com grande repercussão (Godet, 2010).

A nova economia de mercado é caracterizada pela questão do desenvolvimento sustentável (Destatte, 2010), e a antecipação de agir de forma responsável para as futuras gerações, não se restringe a ser sustentável, como também é a ambição da visão estratégica (Coates, Durance \& Godet, 2010).

Assim, para melhorar a qualidade das decisões nos diversos cenários, as empresas precisam desenvolver estratégias para mudar rapidamente, mas em uma perspectiva mais holística. Segundo Porter e Kramer (2011), a criação de valor compartilhado (Creating Shared Value CSV) é uma saída estratégica e uma forma de obter vantagem competitiva no contexto de mudanças constantes em que as empresas se encontram. Ela foi concebida unindo os conceitos de competitividade empresarial com o bem-estar social e o desenvolvimento sustentável. 
No foco empírico, a indústria da construção civil está em constante desenvolvimento e tem tido algumas oscilações nos últimos anos (Conselho Brasileiro de Construção Sustentável [CBCS], 2014). Entretanto, a indústria da construção civil no Brasil tem passado por grandes transformações na última década, como, por exemplo, o desenvolvimento de grandes obras e fortes investimentos imobiliários no país (Mello \& Amorim, 2009). Porém, a situação tem se mostrado diferente nos últimos dois anos, tendo tido problemas em função da falta de investimentos por parte do governo devido à atual crise econômica do país, gerando um maior número de demissões e desaceleração do mercado (Câmara Brasileira da Indústria da Construção [CBIC], 2015).

No caso da construção sustentável, esta possibilita resultados satisfatórios ao tratar das questões econômica, ambiental e social (CBCS, 2014). Essas questões têm impactado a indústria da construção civil e consequentemente vêm gerando grandes incertezas. Assim, cada vez mais, se torna necessário realizar uma análise retrospectiva e prospectiva para identificar as variáveis impactantes para a definição de estratégias que contribuam para decisões futuras.

Portanto, a prospeç̧ão de cenários e a criação de valor compartilhado podem ser fundamentais para a articulação da estratégia da organização dos objetivos que se pretende alcançar em um futuro desejado, pois o que uma organização almeja é implementar uma estratégia que gere vantagem competitiva, e uma forma de obter vantagem competitiva pode ser por meio da criação de valor da empresa com a sociedade.

\subsection{PROBLEMA DE PESQUISA E OBJETIVO}

Diante do exposto, no presente trabalho o problema de pesquisa é a seguinte questão: Quais as estratégias de criação de valor compartilhado a serem adotadas diante de cenários prospectados para a indústria da construção civil no período de 2016-2025?

Com o propósito de responder à questão da pesquisa, definiu-se, como objetivo geral, identificar as estratégias de criação de valor 
compartilhado a serem adotadas diante de cenários prospectados para a indústria da construção civil no período de 2016-2025.

\section{REVISÃO BIBLIOGRÁFICA}

\subsection{CENÁRIOS PROSPECTIVOS}

Alguns futuristas perceberam que a rentabilidade é a melhor condição para o crescimento sustentável, tornando-se necessária atenção maior para globalização, produtividade, inovação, tecnologias e desenvolvimento sustentável (Godet, 2010). De acordo com Destatte (2010), o desenvolvimento sustentável é uma grande oportunidade e desafio para as empresas, e as mudanças de paradigmas, inclusão social, reprocessamento e economia de energia podem produzir soluções inovadoras e rentáveis. As questões do desenvolvimento sustentável e a responsabilidade pelo futuro do planeta podem ser mais bem estudadas e compreendidas com o estudo de cenários.

Ao tratar desse assunto, de fundamental importância no mundo, torna-se necessário atenção maior às decisões estratégicas, principalmente às dimensões econômica, política e sociocultural, tonando possível a integração dos fatores difíceis de quantificar, por exemplo, valores, normas, comportamentos e mudanças institucionais (Destatte, 2010; Godet, 2010). Dessa forma, o exercício de cenários é caracterizado por um conjunto de definições que oferece possibilidades para encontrar pontos de entrada para investigar a complexa questão do desenvolvimento sustentável (Crivits, Paredis, Boulanger, Mutombo, Bauler \& Lefin, 2010).

Algumas particularidades são identificadas nos estudos do futuro como a ação e a reflexão (Coates, Durance \& Godet, 2010); Bezold (2010) acredita que os fatores que influenciam são os objetivos para os cenários, assim como os recursos da organização e o estilo de cultura; e Marcial e Grumbach (2006) visualizam como benefícios a identificação de oportunidades, além da melhora da compreensão do ambiente interno e externo. 
Para tanto, todo o empreendimento é impulsionado por diversos fatores-chave. Identificar e analisar esses fatores é intenção do método de planejamento por cenários. Uma das maneiras de identificá-los é pelas forças motrizes, elementos que direcionam o mapa dos cenários, conduzem e determinam o desenrolar da história. As categorias que compõem as forças motrizes são sociedade, tecnologia, economia, política e ambiente (Godet, 2010). Outra questão é a organização aprofundar-se na análise das variáveis que apresentem sinais de futuras surpresas, ou até mesmo incertezas do tipo de tecnologias, comportamento de clientes, concorrentes, produtos substitutos e surgimento de novos entrantes do setor denominado indústria (Porter, 1986).

O estudo de cenários possui uma extensa variedade de métodos, mas em geral eles incluem passos, etapas, fases, análise de variáveis, seleção de atores e elaboração de cenários múltiplos. Para Godet (2010), um cenário completo contempla seis componentes principais: um título, uma filosofia, variáveis, atores, cenas e trajetórias.

\subsection{CRIAÇÃO DE VALOR COMPARTILHADO (CSV)}

Devido às mudanças impostas não só pelo mundo empresarial, mas também pela sociedade, Porter e Kramer (2011) sugeriram uma nova proposta para as empresas tratarem das questões que envolvem suas responsabilidades em relação aos diferentes tipos de públicos impactados por suas atividades, indo além da Responsabilidade Social Corporativa (Corporate Social Responsibility - CSR). A proposta é baseada no ganho contínuo da empresa por meio de geração de receita, melhoria do valor econômico e da condição da população, satisfazendo as partes envolvidas no processo local e possibilitando um ambiente competitivo (Morais Neto, 2013).

A Criação de Valor Compartilhado (Creating Shared Value - CSV) veio para unir os conceitos de competitividade empresarial e local com o bem-estar social (Porter \& Kramer, 2011). Um dos diferenciais competitivos deste modelo está na solução por meio do valor compartilhado, envolvendo uma dupla criação de valor econômico para empresa e para sociedade, 
visualizando sempre as necessidades das duas partes (Porter, Hills, Pfitzer, Patscheke \& Hawkins, 2011).

Para Bockstette e Stamp (2011), a criação de valor acontece por meio da integração dos três níveis: (1) a criação de valor social, que se refere a investimentos que abordam objetivos sociais e ambientais; (2) a criação de valor compartilhado, que direciona para investimentos em competitividade empresarial em longo prazo, simultânea aos objetivos da empresa; e (3) a criação de valor de negócios, investimentos na competitividade em longo prazo.

\subsubsection{Níveis de Criação de Valor Compartilhado}

A CSV é caracterizada como uma estratégia empresarial e pode compreender três níveis: reconcepção de produtos e mercados, redefinição da produtividade na cadeia de valor e desenvolvimento de clusters (Porter \& Kramer, 2011). Assim, as oportunidades de valor compartilhado vão depender do setor em que a empresa está inserida, da estratégia e de problemas sociais (Porter et al., 2011).

O primeiro nível, reconceber produtos consiste em repensar totalmente a forma como o produto principal foi criado, desenvolvido, embalado e vendido, dada atenção maior na etapa de produção. As oportunidades são dinâmicas e se modificam de acordo com as prioridades da sociedade. Desta forma, a empresa poderá descobrir novas oportunidades de diferenciação e reposicionamento em mercados tradicionais e reconhecer o potencial de mercados novos anteriormente ignorados (Porter et al., 2011; Porter \& Kramer, 2011).

Em relação à redefinição da produtividade na cadeia de valor, o objetivo é descobrir o significado da cadeia de valor, ou seja, um sistema de interdependência de atividades. A cadeia de valor é o conjunto das atividades que a empresa utiliza para realizar seus negócios. Agregar valor nesta cadeia de maneira mais significativa que seus concorrentes torna a empresa mais competitiva; problemas sociais como, por exemplo, uso de água, matéria-prima, saúde, segurança, condições de trabalho, tratamento no ambiente de trabalho etc., podem criar custos financeiros na cadeia de valor. Entretanto, a sinergia aumenta quando a empresa aborda desafios da 
sociedade (energia, transporte, compras, produtividade, distribuição) de uma perspectiva do valor compartilhado e cria novas maneiras de trabalho para enfrentá-los e liberar mais valor econômico (Porter et al., 2011; Porter \& Kramer, 2011).

O terceiro nível consiste no desenvolvimento de clusters. Uma empresa gera valor ao criar clusters visando à melhoria na sua própria produtividade, preenchendo lacunas ou corrigindo falhas nas estruturas em torno do cluster. Para tanto, a empresa deve identificar lacunas e deficiências em áreas como logística, fornecedores, canais de distribuição, treinamento, organização de mercado e instituições de ensino (Porter et al., 2011; Porter \& Kramer, 2011).

Algumas atividades que envolvem questões sociais podem ser combinadas com os recursos que irão criar valor para a empresa (Husted, Allen \& Kock, 2012). Dessa forma, as oportunidades serão criadas por meio de novas abordagens de decisões que geram inovação, crescimento para as empresas e também maiores benefícios para a sociedade (Crane, Palazzo, Spence \& Matten, 2014).

Uma das propostas da CSV é a redefinição das oportunidades estratégicas em longo prazo, contribuindo para o fortalecimento do negócio e agregando valor para os acionistas e stakeholders (Pfitzer, Bockstette \& Stamp, 2013). Outro ponto que se pode equiparar à CSV é a sustentabilidade, devido ao compromisso com a sociedade e também à proposta de redução de custo para ganhos futuros (Bockstette \& Stamp, 2011; Husted et al., 2012; Homrich et al., 2015).

A busca pelas oportunidades de valor compartilhado é uma atividade regular que exige a definição clara dos objetivos socais, incorporando-os nos processos fundamentais, como planejamento estratégico e orçamentação (Pfitzer et al, 2013). Nota-se, ainda, que as empresas estão buscando mais alternativas de criação de valor por meio de estratégias que proporcionam benefícios rentáveis, sociais, ambientais e tangíveis. 


\section{MÉTOdOS E TÉCNICAS DE PESQUISA}

Quanto à classificação, esta pesquisa é epistemologicamente positivista (Collis \& Hussey, 2005) e do tipo teórico-empírica (Demo, 2000), descritiva, de natureza qualitativa e quantitativa (Silverman, 2009).

A pesquisa teve início em agosto de 2015 e foi finalizada em janeiro de 2016, tendo sido empreendida em sete etapas.

A revisão de literatura foi composta de bibliografia sobre cenários, criação de valor compartilhado e estratégia, bem como levantamento do setor da construção civil no Brasil e no estado do Ceará. Levantaram-se, ainda, variáveis que pudessem compor a prospecção de cenários.

$\mathrm{Na}$ etapa de entrevistas, foram utilizados roteiros contendo questões sobre situação atual, variáveis para prospecção e possíveis cenários futuros. Os elementos de pesquisa constituíram-se de cinco especialistas da indústria da construção civil do estado do Ceará (empresário da construção civil, coordenador de curso de engenharia civil - universidade pública e particular, presidente de sindicato e presidente de cooperativa). Os entrevistados serão citados na analises dos dados por meio de códigos (legendas E1, E2, E3, E4 e E5).

Para a terceira etapa, a pesquisa analisou 96 variáveis, sendo 54 variáveis da literatura de cenários e da indústria analisada e 42 variáveis das entrevistas realizadas. Para uso da análise de conteúdo (Bardin, 2009), as variáveis foram classificadas nas categorias: ambiente geral, utilizandose o modelo PESTEL, que se compõe de fatores políticos, econômicos, sociais, tecnológicos, ecológicos e legais (Wright, Mark \& Parnell, 2000); ambiente de tarefa ou específico, contemplando as cinco forças competitivas - clientes, fornecedores, rivais, produtos substitutos e entrantes potenciais (Porter, 1986) -; e, para a análise interna, os recursos tangíveis e intangíveis (Barney \& Hesterly, 2007). Com base nas categorias descritas, foram sumarizadas 41 variáveis, pelo critério de similaridade dos termos (Marinotti, 2000). Para a quarta etapa, dois especialistas (um presidente do sindicato da indústria da construção civil do estado do Ceará e um engenheiro empresário de uma construtora de grande porte) validaram o questionário proposto contendo as 41 variáveis. 
Na quinta etapa, foram encaminhados 42 questionários para as empresas construtoras associadas ao Sindicato da Indústria da Construção Civil do Ceará (Sinduscon-CE), tendo sido obtidas 22 empresas respondentes.

Os questionários foram estruturados com base nos conceitos de pertinência, critério do modelo de Marcial e Grumbach (2006) e de favorabilidade e probabilidade relativos aos critérios do modelo de Blanning e Reinig (1998).

Com relação à pertinência, os especialistas pontuaram em uma escala Likert de 0 a 5 , em que $(0=$ sem influência; $1=$ muito pouca influência; $2=$ pouca influência; 3 = razoável influência; 4= forte influência; e $5=$ extrema influência), sendo esta uma das escalas mais utilizadas em trabalhos acadêmicos (Cooper \& Schindler, 2008). Os especialistas opinaram sobre a pertinência (importância) da ocorrência ou não de determinado evento na construção dos cenários. O critério pertinência era independente da probabilidade de ocorrência do evento (Marcial \& Grumbach, 2006).

No caso da favorabilidade, significava o quanto a variável seria favorável para a construção dos cenários. Para esse critério, utilizou-se a escala (0 a 100\%, com intervalos de 10 em 10\%). Para o critério da probabilidade de ocorrência das variáveis na prospecção dos cenários, também foi utilizada a escala de 0 a 100\%, com intervalos de 10 em 10\% (Blanning \& Reinig, 1998). A escolha pela escala Likert se deu devido às vantagens: primeiro é fácil para o pesquisador construí-la e aplicá-la, assim como é fácil para o entrevistado entendê-la, tornando possível o rápido retorno do entrevistado (Malhotra, Rocha, Altheman \& Borges, 2005).

O questionário tinha a seguinte estrutura: (1) categoria ambiente geral com 19 variáveis; (2) categoria ambiente indústria com sete variáveis; e (3) variáveis da empresa (recursos) com 15 variáveis para análise. Tanto na fase do pré-teste quanto na fase da coleta de campo, os questionários foram encaminhados por meio da plataforma online survey monkey. Os dados foram exportados para o Excel para o cálculo da média, desvio padrão e coeficiente de variação de todas as variáveis (Larson \& Farber, 2010). 
Na sexta etapa, para o recenseamento das variáveis, contou-se com dois filtros. No primeiro filtro foi utilizado o método de consenso de Godet (1993), que tem como critério de corte a pontuação do coeficiente de variação (=) igual ou (>) maior que $20 \%$; e o segundo filtro foi pelo critério de corte referente à média das médias de todas as variáveis para identificar uma média geral de corte. Portanto, permaneceram as variáveis que possuíram o coeficiente de variação $(=)$ igual ou $(<)$ menor $26 \%$, detalhado na próxima seção. Após os dois filtros, permaneceram 23 variáveis para a construção dos cenários.

Para a composição dos cenários, utilizou-se a metodologia de Blanning e Reinig (1998), que classifica os cenários em três tipos: otimista, pessimista e realista. Para a descrição de cada cenário, buscou-se suporte em notícias divulgadas em diversos tipos de mídia (vídeo, áudio, impresso e web), nas entrevistas exploratórias de profundidade realizadas com os cinco especialistas na fase de coleta de dados, em artigos e relatórios que pudessem ter registros e projeções sobre o comportamento das variáveis selecionadas.

Por fim, na sétima etapa foram identificadas as estratégias de CSV (Porter \& Kramer, 2011) baseadas nas variáveis com maior favorabilidade e probabilidade.

\section{APRESENTAÇÃo E ANÁLISE DE RESULTADOS}

\subsection{DEFINIÇÃO DAS VARIÁVEIS}

Como forma de redução da quantidade de variáveis, calcularam-se no Excel a média e o desvio padrão de todas as variáveis da classificação pertinência para encontrar o coeficiente de variação.

O primeiro filtro para recenseamento de variáveis foi feito para excluir o número de 41 variáveis, que dificultaria a construção dos cenários. Para minimizar o efeito, utilizou-se o método de consenso de Godet (1993), que tem como critério de corte a pontuação do coeficiente de variação (CV) (=) igual ou (>) maior que 20\%. Entretanto, ao aplicar o método de consenso, identificou-se que algumas variáveis ficaram com os CVs bem 
próximos, conforme se apresenta na Tabela 1, na coluna de CV. Assim, de forma subsequente, aplicou-se uma análise qualitativa para essas variáveis, que apresentavam próximas dispersões e, como critério de nota de corte, ou seja, critério de exclusão das variáveis, foi aplicada a média dos coeficientes de variação (obtendo-se como resultado o valor de 0,26 ) (Oliveira \& Forte, 2009). Portanto, as variáveis que possuíssem o CV menor que 0,26 (marcadas na Tabela $1 \mathrm{em}$ itálico) foram consideradas de relevância para a composição dos cenários, ou seja, pouca discrepância de opiniões. Assim, permaneceram 23 variáveis para a composição dos cenários. As demais 18 variáveis foram excluídas.

Tabela 1: Variáveis Pertinência Filtro 1 e 2

\begin{tabular}{|c|c|c|c|c|c|c|}
\hline Quantidade & Categoria & $\begin{array}{l}\text { Número } \\
\text { (código) }\end{array}$ & Variáveis & Média & $\begin{array}{l}\text { Desvio } \\
\text { Padrão }\end{array}$ & CV \\
\hline \multirow[t]{19}{*}{19} & \multirow[t]{19}{*}{ Ambiente Geral } & 1 & $\begin{array}{l}\text { Tendências para construções sustentáveis } \\
\text { (tecnologia) }\end{array}$ & 4,09 & 0,68 & 0,17 \\
\hline & & 2 & Certificação das obras sustentáveis & 3,95 & 0,79 & 0,20 \\
\hline & & 3 & Desenvolvimento sustentável & 4,14 & 0,64 & 0,15 \\
\hline & & 4 & Eficiência energética & 3,91 & 0,92 & 0,24 \\
\hline & & 5 & Problemas ambientais & 3,91 & 1,06 & 0,27 \\
\hline & & 6 & Demografia & 3,59 & 0,85 & 0,24 \\
\hline & & 7 & Classe social & 3,67 & 1,02 & 0,28 \\
\hline & & 8 & Problemas sociais & 3,48 & 1,21 & 0,35 \\
\hline & & 9 & Sociedade/ comunidade & 3,90 & 0,54 & 0,14 \\
\hline & & 10 & Poder aquisitivo & 3,82 & 0,91 & 0,24 \\
\hline & & 11 & Infraestrutura local & 3,68 & 0,99 & 0,27 \\
\hline & & 12 & Novas ferramentas de gestão & 4,23 & 0,53 & 0,13 \\
\hline & & 13 & $\begin{array}{l}\text { Política, legislação e normas } \\
\text { governamentais }\end{array}$ & 4,14 & 0,77 & 0,19 \\
\hline & & 14 & Apoio do sindicato & 3,91 & 1,15 & 0,29 \\
\hline & & 15 & Programas do governo (habitação) & 3,82 & 0,91 & 0,24 \\
\hline & & 16 & Crise financeira & 4,00 & 1,35 & 0,34 \\
\hline & & 17 & Oferta de crédito e financiamentos & 4,59 & 0,73 & 0,16 \\
\hline & & 18 & Aumento da participação do PIB & 3,64 & 1,09 & 0,30 \\
\hline & & 19 & Cenário passado & 3,09 & 1,19 & 0,39 \\
\hline \multirow[t]{7}{*}{7} & \multirow{7}{*}{$\begin{array}{l}\text { Ambiente da } \\
\text { Indústria }\end{array}$} & 20 & Mudança de paradigma & 3,45 & 1,1 & 0,32 \\
\hline & & 21 & Aumento da concorrência & 3,55 & 0,91 & 0,26 \\
\hline & & 22 & Poder do cliente & 3,82 & 0,91 & 0,24 \\
\hline & & 23 & Mudanças de materiais & 3,45 & 1,1 & 0,32 \\
\hline & & 24 & Novos entrantes & 3,33 & 1,02 & 0,30 \\
\hline & & 25 & Aumento do poder do fornecedor & 3,36 & 1,09 & 0,32 \\
\hline & & 26 & Formação de clusters & 3,23 & 1,02 & 0,32 \\
\hline \multirow[t]{15}{*}{15} & \multirow{15}{*}{$\begin{array}{l}\text { Variáveis da } \\
\text { Empresa }\end{array}$} & 27 & Filantropia & 2,55 & 1,14 & 0,45 \\
\hline & & 28 & Responsabilidade social corporativa & 3,36 & 1,14 & 0,34 \\
\hline & & 29 & Cultura organizacional & 4,00 & 0,82 & 0,20 \\
\hline & & 30 & Planejamento estratégico & 4,14 & 0,94 & 0,23 \\
\hline & & 31 & Ação estratégica & 3,95 & 0,92 & 0,23 \\
\hline & & 32 & $\begin{array}{l}\text { Desenvolvimento de recursos da } \\
\text { organização }\end{array}$ & 3,91 & 0,61 & 0,16 \\
\hline & & 33 & Desenvolvimento de novos mercados & 3,77 & 0,69 & 0,18 \\
\hline & & 34 & Especialistas em construções sustentáveis & 3,36 & 1,26 & 0,37 \\
\hline & & 35 & $\begin{array}{l}\text { Aumento do lucro em função da construção } \\
\text { sustentável }\end{array}$ & 3,41 & 1,44 & 0,42 \\
\hline & & 36 & Maior compromisso ambiental & 3,82 & 0,8 & 0,21 \\
\hline & & 37 & Parcerias com stakeholders & 3,50 & 0,91 & 0,26 \\
\hline & & 38 & Diminuição dos custos operacionais & 4,41 & 0,67 & 0,15 \\
\hline & & 39 & $\begin{array}{l}\text { Inovação em tecnologias e em } \\
\text { desenvolvimento de novos materiais }\end{array}$ & 4,18 & 0,85 & 0,20 \\
\hline & & 40 & Balanços sociais & 3,27 & 1,03 & 0,32 \\
\hline & & 41 & Vantagem competitiva & 4,05 & 0,72 & 0,18 \\
\hline
\end{tabular}

Fonte: Dados da pesquisa 


\section{.2 PROSPECÇÃO DOS CENÁRIOS}

Nesta etapa, propôs-se analisar os dados referentes a dois critérios do questionário - favorabilidade e probabilidade - com notas de $0 \%$ a 100\%. Cada respondente analisou a variável por meio do critério de quanto a variável seria favorável para os cenários de 2016 a 2025 e a probabilidade de ocorrência de cada variável para os cenários de 2016 a 2025. Na Tabela 2, apresentam-se as 23 variáveis que resultaram da fase anterior e a análise da classificação favorabilidade e probabilidade.

Tabela 2: Variáveis finais favorabilidade e probabilidade

\begin{tabular}{c|l|c|c}
\hline $\begin{array}{c}\text { Número } \\
\text { (código) }\end{array}$ & \multicolumn{1}{|c|}{ Variáveis } & Favorabilidade & Probabilidade \\
& & Média & Média \\
\hline $\mathbf{1}$ & $\begin{array}{l}\text { Tendências para construções sustentáveis } \\
\text { (tecnologia) }\end{array}$ & $76 \%$ & $70 \%$ \\
\hline $\mathbf{2}$ & Certificação das obras sustentáveis & $70 \%$ & $70 \%$ \\
\hline $\mathbf{3}$ & Desenvolvimento sustentável & $71 \%$ & $68 \%$ \\
\hline $\mathbf{4}$ & Eficiência energética & $75 \%$ & $71 \%$ \\
\hline $\mathbf{6}$ & Demografia & $67 \%$ & $62 \%$ \\
\hline $\mathbf{9}$ & Sociedade/ comunidade & $69 \%$ & $67 \%$ \\
\hline $\mathbf{1 0}$ & Poder aquisitivo & $66 \%$ & $62 \%$ \\
\hline $\mathbf{1 2}$ & Novas ferramentas de gestão & $77 \%$ & $75 \%$ \\
\hline $\mathbf{1 3}$ & Política, legislação e normas governamentais & $72 \%$ & $67 \%$ \\
\hline $\mathbf{1 7}$ & Programas do governo (habitação) & $71 \%$ & $66 \%$ \\
\hline $\mathbf{2 1}$ & Oferta de crédito e financiamentos & $78 \%$ & $71 \%$ \\
\hline $\mathbf{2 2}$ & Aumento da concorrência & $66 \%$ & $69 \%$ \\
\hline $\mathbf{2 9}$ & Poder do cliente & $66 \%$ & $72 \%$ \\
\hline $\mathbf{3 0}$ & Pultura organizacional & $73 \%$ & $69 \%$ \\
\hline $\mathbf{3 1}$ & Ação estratégica & $75 \%$ & $67 \%$ \\
\hline $\mathbf{3 2}$ & Desenvolvimento de recursos da organização & $77 \%$ & $68 \%$ \\
\hline $\mathbf{3 3}$ & Desenvolvimento de novos mercados & $70 \%$ & $66 \%$ \\
\hline $\mathbf{3 6}$ & Maior compromisso ambiental & $72 \%$ & $64 \%$ \\
\hline $\mathbf{3 7}$ & Parcerias com stakeholders & $66 \%$ & $64 \%$ \\
\hline $\mathbf{3 8}$ & Diminuição dos custos operacionais & $80 \%$ & $60 \%$ \\
\hline $\mathbf{3 9}$ & Inovação em tecnologias e em desenvolvimento & $76 \%$ & $71 \%$ \\
\hline $\mathbf{4 1}$ & de novos materiais & $70 \%$ \\
\hline & Vantagem competitiva & & $68 \%$ \\
\hline
\end{tabular}

Fonte: Dados da pesquisa

Na sequência, os dados relativos às duas classificações foram exportados para uma matriz cujo eixo horizontal representa a probabilidade (P) e o eixo vertical representa se as variáveis são favoráveis (F) ou não. 
Cada ponto dentro da matriz caracterizava uma variável e correspondia à média obtida das notas dos especialistas para cada variável analisada. Devido às variáveis ficarem acima do ponto 50, tanto no eixo vertical (favorabilidade) como no eixo horizontal (probabilidade), essa condição dificultou o posicionamento das variáveis para os três cenários. Assim, estabeleceu-se uma análise mais sensível da situação, apresentando-se um novo quadrante para análise das variáveis. O eixo vertical (favorabilidade) passa a ser analisado a partir do valor de 50\%, da mesma forma foi feito para o eixo horizontal, a partir de 50\% (probabilidade). A análise foi realizada dessa forma, diferentemente da metodologia inicial de Blanning e Reinig (1998), para identificar com mais precisão a localização das variáveis e o cenário pertencente (Gráfico 1).

As oito variáveis que ocupam o quadrante 1 são: (1) Tendências para construções sustentáveis (tecnologia); (4) Eficiência energética; (17) Oferta de crédito e financiamentos; (30) Planejamento estratégico; (31) Ação estratégica; (32) Desenvolvimento de recursos da organização; (38) Diminuição dos custos operacionais; e (39) Inovação em tecnologias e em desenvolvimento de novos materiais.

Apenas a variável (12), Novas ferramentas de gestão, ocupa o segundo quadrante. Vale ressaltar que essa variável ficou no meio da linha entre os quadrantes 1 e 2 .

No caso do quadrante 3, nenhuma variável foi evidenciada; já no quadrante 4, as variáveis são: (2) Certificação das obras sustentáveis; (3) Desenvolvimento sustentável; (6) Demografia; (9) Sociedade/ comunidade; (10) Poder aquisitivo; (13) Politica, legislação e normas governamentais; (15) Programas do governo - habitação; (21) Aumento da concorrência; (22) Poder do cliente; (29) Cultura organizacional; (33) Desenvolvimento de novos mercados; (36) Maior compromisso ambiental; (37) Parcerias com stakeholders; e (41) Vantagem competitiva. 


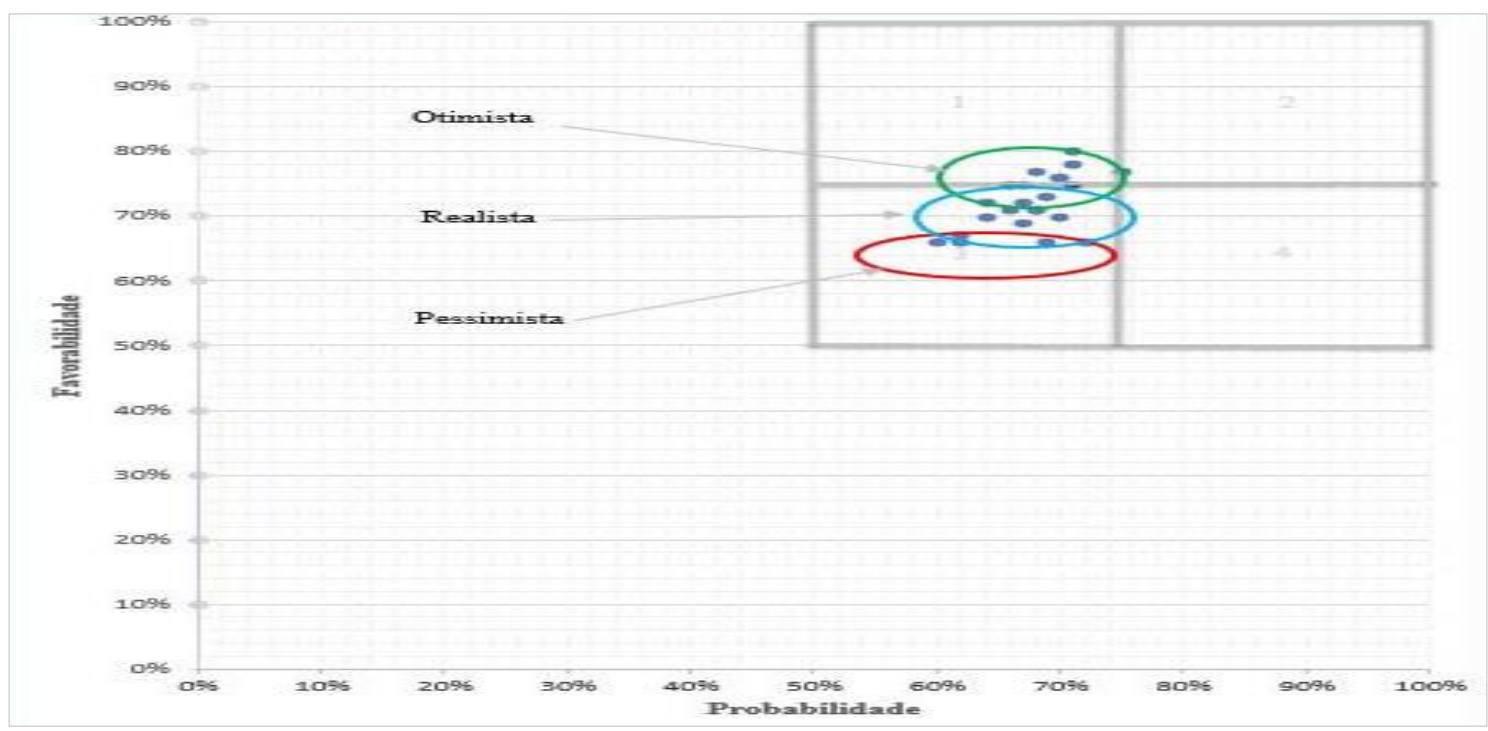

\section{Gráfico 1: Identificação das variáveis para a construção dos cenários}

Fonte: Resultados da pesquisa

Para a composição dos cenários, utilizou-se a metodologia de Blanning e Reinig (1998) que classifica os cenários em três tipos: otimista, para este cenário utilizaram-se as variáveis que apresentaram elevada probabilidade de ocorrência e que foram muito favoráveis; pessimista, no caso deste cenário, foram utilizadas as variáveis que apresentaram médias e elevadas probabilidades e que também eram desfavoráveis; e realista, para este cenário, utilizaram-se as variáveis com grande probabilidade de ocorrência e que apresentaram alto percentual de favorabilidade.

\subsection{CENÁRIOS OBTIDOS}

\subsubsection{Cenário Otimista}

Compõe este cenário as variáveis (38), (17), (12), (31), (1), (39), (4), (30), (32) e (29) (Quadro 1). 


\section{OTIMISTA}

O Cenário Otimista é composto pelas variáveis que apresentam elevada possibilidade de ocorrência e que são muito favoráveis para a empresa. Tem-se a variável 38 (Diminuição dos custos operacionais), que indica o maior percentual de favorabilidade. É uma variável que tem grande representatividade para a indústria, pois engloba boa parte dos subsetores da cadeia produtiva, uma vez que a diminuição dos custos operacionais é influenciado por outras variáveis. Na sequência, a variável 17 (Oferta de crédito e financiamentos), neste caso das ofertas de créditos, há realmente grande influência devido às melhorias que a indústria pode adquirir. No caso dos bancos, estes disponibilizam recursos financeiros para construtoras realizarem grandes obras, assim como disponibilizam créditos de financiamentos também para a população. Esta variável tem relação com o Programa Minha Casa, Minha Vida (PMCMV) e a sua importância é atribuída para a redução do déficit habitacional, suprindo parte da demanda por moradias da população com menores faixas de renda, impactando também a geração de emprego e renda. As variáveis 12 (Novas ferramentas de gestão), 30 (Planejamento estratégico) e 31 (Ação estratégica) indicam que a indústria da construção precisa aderir a novas ferramentas para desempenhar-se melhor. A variável 1 (Tendências para construções sustentáveis - tecnologia) é uma variável que impacta ações de cunho social, compete também a adequação às exigências do governo. Na variável 39 (Inovação em tecnologias e em desenvolvimento de novos materiais), é interessante o incentivo para promover a pesquisa para o desenvolvimento e inovação de novos materiais e componentes. No caso da variável 4 (Eficiência energética), é um grande desafio na indústria da construção, pois é um dos setores com maior demanda de energia. Um dos objetivos é aumentar a eficiência energética durante e após a obra. As variáveis a seguir são as que as empresas podem modificar internamente, ou reforçar quando for o caso, para melhorar sua posição no mercado: a variável 29 (Cultura organizacional) e a variável 32 (Desenvolvimento de recursos da organização). Nota-se que a questão cultural gera uma barreira, pois existe grande resistência cultural a novos métodos construtivos, A questão cultural gera grandes incertezas e atrasa a inserção de inovação em novas tecnologias. Isso ocorre porque existe uma barreira de aceitação do mercado.

\section{Quadro 1: Cenário otimista}

Fonte: Resultados da pesquisa

Segundo o especialista E4 (2015), gestão é necessário. São fundamentais a gestão e a inovação. A gestão para ter um controle maior nos resultados e também nos processos para reduzir as perdas. É necessário que haja mudança tecnológica nos processos construtivos e nos materiais, fortalecendo a utilização do uso racional de recursos (CNI, 2012).

\subsubsection{Cenário Pessimista}

As variáveis que compõem o cenário pessimista - (6), (10), (37), (21) e (22) - são desfavoráveis às empresas e requerem atitudes no presente para minimizar seus efeitos no futuro (Quadro 2). 


\section{PESSIMISTA}

O Cenário Pessimista é constituído por eventos que apresentam médias e elevadas probabilidades de virem a ocorrer e que sejam desfavoráveis para o segmento. A variável 6 (Demografia) não é uma variável que o empresário da indústria da construção pode controlar e/ou na qual possa interferir. Porém, esta variável possibilita quantificar dados pertinentes da população. Desta forma, é possível preparar-se para os seus efeitos, porém não para a causa, pois não depende da atuação do empresário. As variáveis 10 (Poder aquisitivo) e 22 (Poder do cliente) são desfavoráveis às empresas, mas podem ser alteradas por ações postas em prática no presente. São duas variáveis que não estão sob o controle dos empresários, mas que influenciam diretamente nos resultados desta indústria. A variável 21 (Aumento da concorrência), na indústria da construção civil, tem característica ainda artesanal, porém algumas empresas reagem de forma competitiva no mercado e buscam sobressair-se dos demais concorrentes. A variável 37 (Parcerias com stakeholders) pode contribuir com o setor por meio de parcerias com instituições, clientes, fornecedores, sindicatos, cooperativas e governo.

\section{Quadro 2: Cenário pessimista}

Fonte: Resultados da pesquisa

A indústria da construção civil tem características ainda artesanais, porém algumas empresas reagem de forma competitiva no mercado e buscam sobressair-se às demais concorrentes, por exemplo, importam maquinários e utilizam mais tecnologias no seu processo construtivo e um dos diferencias são as adequações à construção verde, que se dá por meio de inovações, mudanças de matéria-prima e mudança no processo construtivo (E1, 2015; E3, 2015). Essas mudanças devem ser tomadas no presente e são de competência da empresa. A questão de adequar-se às novas exigências do mercado é uma condição necessária para as empresas se manterem atuando no mercado e driblarem a crise.

As parcerias com os stakeholders podem contribuir com o setor por meio de parcerias com instituições, clientes, fornecedores, sindicatos, cooperativas e governo. Vale ressaltar que essas parcerias podem ser um diferencial também para compras de matéria-prima, maquinários, software (E3, 2015; E4, 2015) e, além disso, geram resultados empresariais e sociais devido à realização dessa integração (Porter \& Kramer, 2011).

Acredita-se que as parcerias podem promover a conscientização da população sobre a necessidade de criação de novos hábitos de consumo, como água e energia, com prioridade para ações duradouras (CBCS, 2014; E5, 2015). Ainda, as alianças estratégicas podem ser feitas por meio dessas parcerias e podem alavancar os resultados empresariais.

O compromisso ambiental se dá pelo compromisso da empresa e de seus colaboradores em relação aos impactos ambientais, assim como pela responsabilidade da empresa na promoção de trabalho seguro e saudável, 
reduzindo impactos ambientais (CBCS, 2014). Assim, reciclar, agregar a sociedade nos trabalhos para a criação de valor, utilizar novos modelos tecnológicos e mudar produtos tradicionais para sustentáveis contribuem para a empresa e para o meio ambiente (CBIC, 2015; E4, 2015).

\subsubsection{Cenário Realista}

As variáveis que compõem o cenário realista são (2), (3), (9), (13), (15), (21), (22), (29), (33), (36) e (41) (Quadro 3).

\section{REALISTA}

O Cenário Realista é constituído por eventos com grande probabilidade de ocorrerem, podendo apresentar-se como favoráveis ou não para as empresas. A variável 3 (Desenvolvimento sustentável) e a variável 13 (Politica, legislação e normas governamentais) implicam mudanças de comportamento e adequação às normas, às tendências e às novas exigências do mercado. As variáveis 33 (Desenvolvimento de novos mercados) e 36 (Maior compromisso ambiental) refletem a adequação da indústria da construção aos apelos ambientais. É possível identificar novos mercados para adquirir novos produtos e agregar serviços diferenciados. A variável 2 (Certificações das obras sustentáveis) é uma saída estratégica para o setor. À medida que a construção verde se populariza, mais inovações podem ser desenvolvidas, mais obras podem ser realizadas e vendidas. A variável 29 (Cultura organizacional) pode ser uma oportunidade para os empresários que estão dispostos à mudança. A variável 41 (Vantagem competitiva) pode ser atribuída às mudanças de novos produtos e a adequações no processo construtivo. Algumas habilidades, assim como o conhecimento especifico para a execução de atividades, podem acarretar maiores forças para a competitividade. No caso da variável 9 (Sociedade/ comunidade), um dos benefícios e vantagens adquiridas para a sociedade e comunidade por meio de práticas de sustentabilidade no setor imobiliário são: melhor qualidade de vida, responsabilidade social e ambiental, qualidade de concepção e projeto e mudanças de paradigmas. Na variável 15 (Programas do governo - habitação), percebe-se, que as questões sociais estão ganhando força como condicionantes para que empresas do setor possam atuar nesses programas. Os programas do governo, por exemplo, Programa de Aceleração do Crescimento (PAC) e o programa Minha Casa Minha Vida (PMCMV), contribuem para grandes obras na indústria da construção civil e muitas construtoras têm sua movimentação financeira em maior volume devido a eles. As variáveis 21 (Aumento da concorrência) e 22 (Poder do cliente) indicaram para os cenários realista e pessimista. São variáveis que fogem do controle da empresa, mas que, se forem mais bem exploradas, podem ter ganhos satisfatórios.

\section{Quadro 3: Cenário realista}

Fonte: Resultados da pesquisa

As certificações sustentáveis aparecem como uma ferramenta de suma importância para promover a construção sustentável (CBIC, 2015). Além disso, alguns dos principais obstáculos ao desenvolvimento da construção civil são: falta de cultura voltada para o desenvolvimento da qualidade e da produtividade nas operações do setor; crescente descompasso entre as capacidades da mão de obra disponível no setor em relação às exigências do seu processo tecnológico; carência de informações 
e de garantias sobre o real desempenho de produtos e de serviços; e indicadores de desempenho das atividades desenvolvidas nas obras (E2, 2015).

\subsection{ESTRATÉGIAS DE CSV}

Com base nos resultados e nas oportunidades identificadas por meio dos cenários prospectados, no Quadro 4, apresentam-se estratégias de CSV que servirão de insumo e apoio para a tomada de decisão dos empresários da indústria da construção civil no estado do Ceará. Essas estratégias foram relacionadas com os cenários, são de cunho socialmente responsável, sustentável e empresarial e visam contribuir à consolidação de uma construção sustentável.

As estratégias foram agrupadas de acordo com os três níveis do modelo CSV de Porter e Kramer (2011).

\begin{tabular}{|c|c|c|c|c|c|c|}
\hline $\begin{array}{l}\text { Níveis de } \\
\text { CSV }\end{array}$ & Cenário & Variável & & Estratégia & $\begin{array}{c}\text { Resultados } \\
\text { de } \\
\text { negócios }\end{array}$ & $\begin{array}{l}\text { Resultados } \\
\text { sociais }\end{array}$ \\
\hline \multirow{4}{*}{$\begin{array}{c}\text { Nível } 1 \\
\text { Reconceb } \\
\text { er } \\
\text { produtos } \\
\text { e } \\
\text { mercados }\end{array}$} & Otimista & $\begin{array}{l}\text { Tendências para } \\
\text { construções } \\
\text { sustentáveis - } \\
\text { tecnologia }\end{array}$ & \multirow[t]{2}{*}{$\mathrm{E} 1$} & \multirow{2}{*}{$\begin{array}{l}\text { Incentivos para } \\
\text { empresas que } \\
\text { aderirem a } \\
\text { tecnologias para } \\
\text { realizar uma } \\
\text { construção } \\
\text { sustentável }\end{array}$} & $\begin{array}{l}\text { Eficiência no } \\
\text { processo } \\
\text { construtivo }\end{array}$ & $\begin{array}{c}\text { Integração da } \\
\text { empresa com a } \\
\text { sociedade, } \\
\text { possibilitando } \\
\text { novas } \\
\text { oportunidade } \\
\text { de trabalho }\end{array}$ \\
\hline & Otimista & $\begin{array}{l}\text { Inovação em } \\
\text { tecnologias e } \\
\text { em desenvolvi } \\
\text { mento de novos } \\
\text { materiais }\end{array}$ & & & $\begin{array}{l}\text { Expansão } \\
\text { dos } \\
\text { negócios e } \\
\text { diversificaçã } \\
\text { o de } \\
\text { mercados }\end{array}$ & Inclusão social \\
\hline & Realista & $\begin{array}{l}\text { Certificação de } \\
\text { obras } \\
\text { sustentáveis }\end{array}$ & & & $\begin{array}{l}\text { Obra limpa, } \\
\text { sem } \\
\text { desperdícios } \\
\text {, maior } \\
\text { qualidade e } \\
\text { durabilidade }\end{array}$ & $\begin{array}{c}\text { Novos } \\
\text { comportament } \\
\text { os da } \\
\text { população }\end{array}$ \\
\hline & Realista & $\begin{array}{l}\text { Desenvolvi } \\
\text { mento de novos } \\
\text { mercados }\end{array}$ & E2 & $\begin{array}{l}\text { materiais e } \\
\text { certificações para } \\
\text { uma construção } \\
\text { ecologicamente } \\
\text { sustentável }\end{array}$ & $\begin{array}{l}\text { Desenvolvi } \\
\text { mento de } \\
\text { novos } \\
\text { produtos }\end{array}$ & $\begin{array}{c}\text { Garantia de } \\
\text { segurança para } \\
\text { os } \\
\text { compradores e } \\
\text { maior } \\
\text { credibilidade } \\
\text { do imóvel, } \\
\text { consequentem } \\
\text { ente, maior } \\
\text { segurança para } \\
\text { a sociedade }\end{array}$ \\
\hline
\end{tabular}




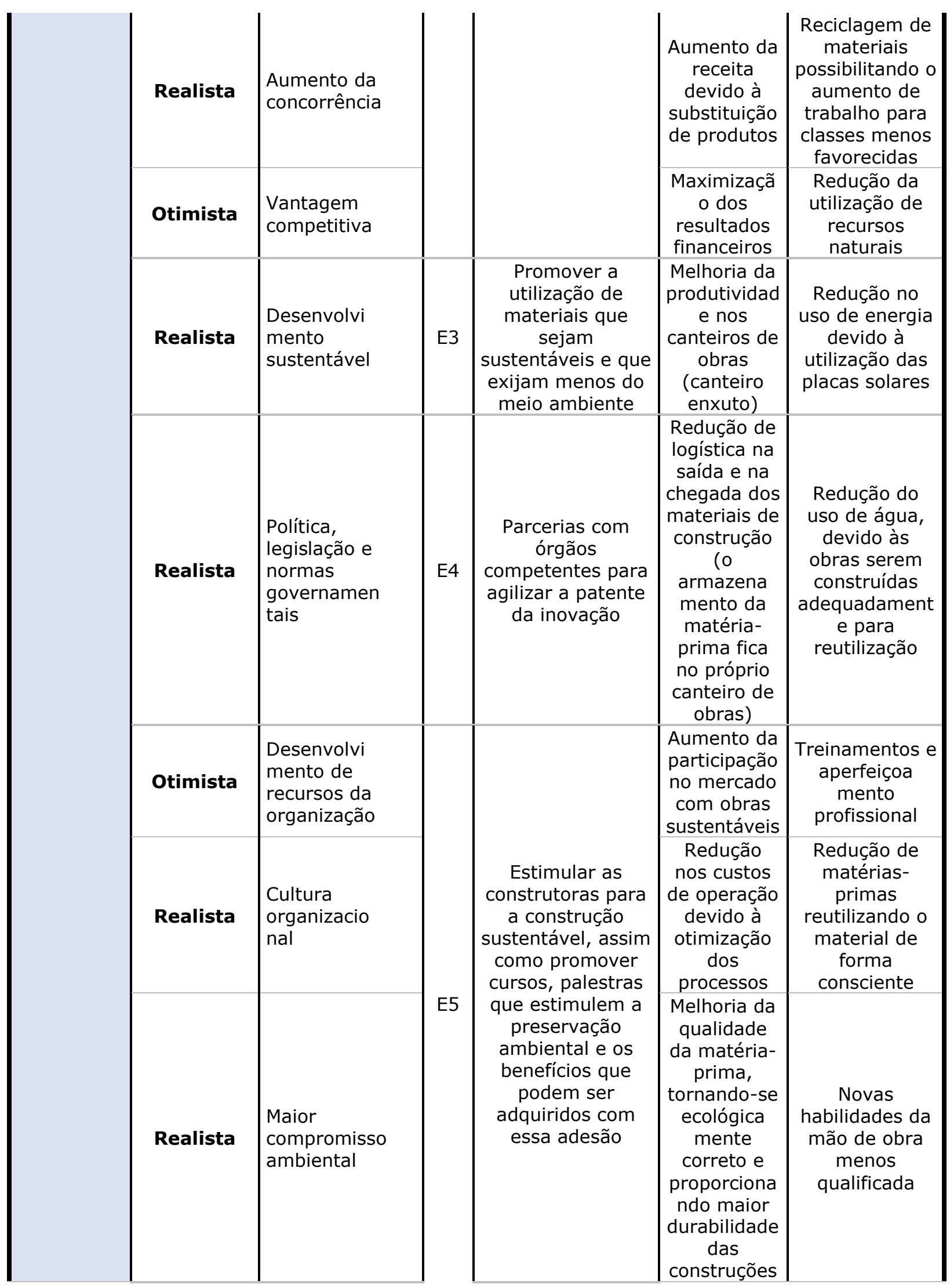

Continua 


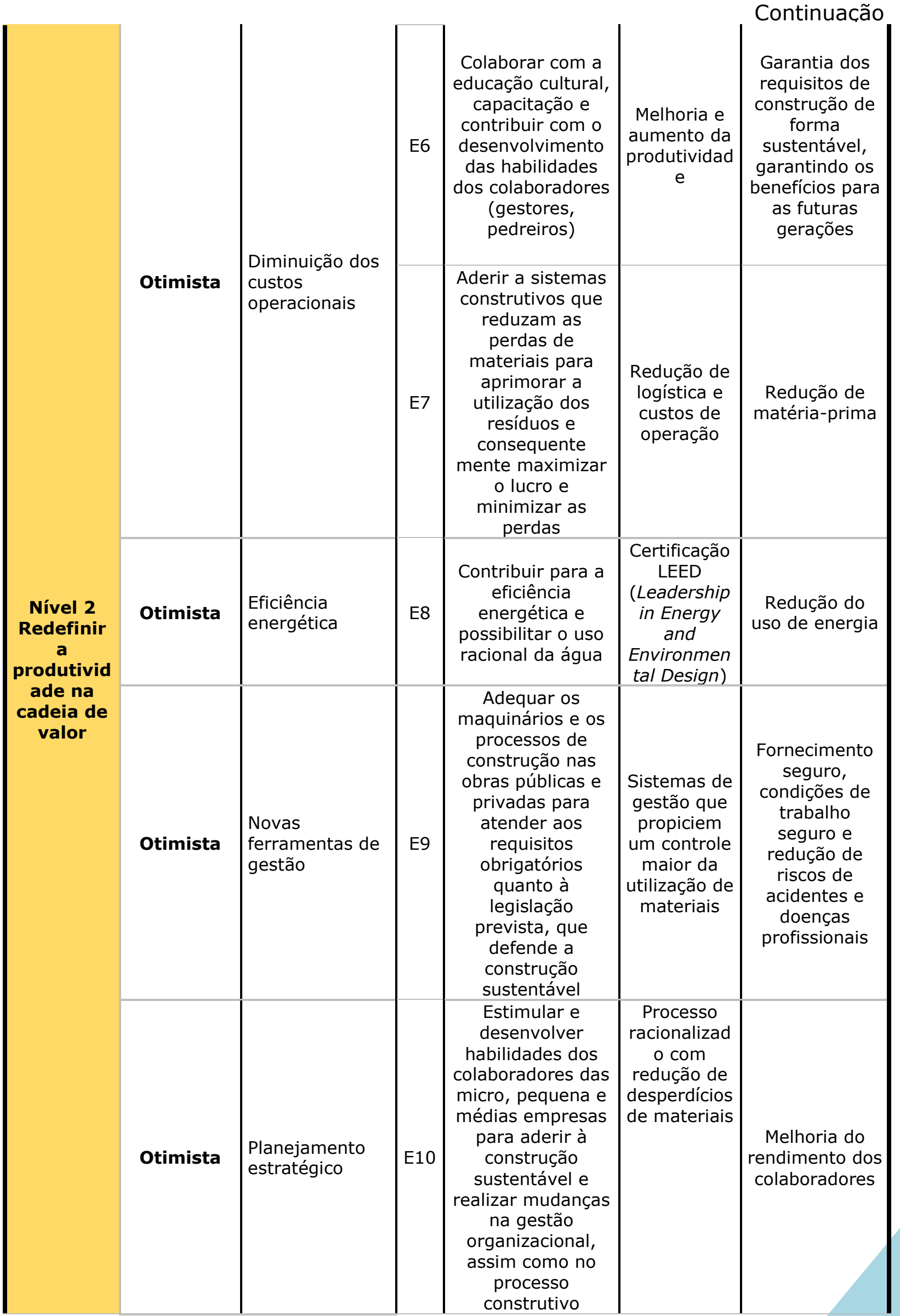




\begin{tabular}{|c|c|c|c|c|c|c|}
\hline & & & E11 & $\begin{array}{c}\text { Mudança de } \\
\text { legislação para } \\
\text { facilitar a } \\
\text { importação de } \\
\text { maquinários para } \\
\text { proporcionar } \\
\text { agilidade no } \\
\text { processo } \\
\text { construtivo no } \\
\text { canteiro de obra }\end{array}$ & $\begin{array}{c}\text { Facilidade } \\
\text { de inserção } \\
\text { de novos } \\
\text { maquinários }\end{array}$ & $\begin{array}{l}\text { Continuaçãc } \\
\text { Novas } \\
\text { possibilidades } \\
\text { de cursos e } \\
\text { desenvolvi } \\
\text { mento do } \\
\text { capital } \\
\text { intelectual do } \\
\text { colaborador }\end{array}$ \\
\hline & Otimista & $\begin{array}{l}\text { Ação } \\
\text { estratégica }\end{array}$ & E12 & \begin{tabular}{|c|} 
Propor \\
adequações nas \\
etapas do \\
processo \\
construtivo e \\
realizar a \\
reciclagem \\
durante todo o \\
período estimado \\
da obra. Promover \\
a reciclagem nos \\
canteiros de obras
\end{tabular} & $\begin{array}{l}\text { Redução do } \\
\text { custo de } \\
\text { materiais } \\
\text { em função } \\
\text { da redução } \\
\text { do } \\
\text { desperdício }\end{array}$ & $\begin{array}{l}\text { Melhoria da } \\
\text { educação dos } \\
\text { funcionários, } \\
\text { sabendo } \\
\text { aproveitar de } \\
\text { forma correta a } \\
\text { matéria-prima }\end{array}$ \\
\hline \multirow{5}{*}{$\begin{array}{c}\text { Nível } 3 \\
\text { Permitir o } \\
\text { desenvolv } \\
\text { imento de } \\
\text { clusters }\end{array}$} & Otimista & $\begin{array}{l}\text { Ofertas de } \\
\text { créditos e } \\
\text { financiamento }\end{array}$ & E13 & $\begin{array}{c}\text { Promover } \\
\text { parcerias com } \\
\text { empresas e } \\
\text { universidades } \\
\text { estrangeiras } \\
\text { buscando o } \\
\text { crescimento } \\
\text { contínuo por meio } \\
\text { de inovações de } \\
\text { produtos e } \\
\text { processos que } \\
\text { favoreçam a } \\
\text { construção civil no } \\
\text { estado do Ceará }\end{array}$ & $\begin{array}{c}\text { Melhoria de } \\
\text { infraestrutur } \\
\text { a }\end{array}$ & $\begin{array}{l}\text { Melhoria da } \\
\text { saúde }\end{array}$ \\
\hline & Pessimista & Poder aquisitivo & E14 & $\begin{array}{c}\text { Criar políticas de } \\
\text { incentivo fiscais e } \\
\text { mudanças nas } \\
\text { legislações }\end{array}$ & \multirow[b]{2}{*}{$\begin{array}{l}\text { Melhoria do } \\
\text { acesso à } \\
\text { força de } \\
\text { trabalho }\end{array}$} & \multirow[b]{2}{*}{$\begin{array}{l}\text { Melhorias nos } \\
\text { investimentos } \\
\text { sociais }\end{array}$} \\
\hline & Pessimista & Poder do cliente & E15 & $\begin{array}{c}\text { Promover a } \\
\text { integração das } \\
\text { empresas com os } \\
\text { sindicatos, } \\
\text { cooperativas e } \\
\text { demais órgãos } \\
\text { competentes }\end{array}$ & & \\
\hline & Pessimista & $\begin{array}{l}\text { Parcerias com } \\
\text { stakeholders }\end{array}$ & E16 & $\begin{array}{c}\text { Criar um cluster } \\
\text { para a construção } \\
\text { civil sustentável } \\
\text { no estado do } \\
\text { Ceará }\end{array}$ & \multirow[b]{2}{*}{$\begin{array}{l}\text { Melhoria da } \\
\text { rentabilidad } \\
\text { e financeira }\end{array}$} & \multirow[b]{2}{*}{$\begin{array}{l}\text { Aumento de } \\
\text { criação de } \\
\text { empregos }\end{array}$} \\
\hline & Realista & $\begin{array}{l}\text { Sociedade/com } \\
\text { unidade }\end{array}$ & E17 & $\begin{array}{l}\text { Promover debates } \\
\text { e cursos para } \\
\text { conscientização } \\
\text { sobre a } \\
\text { importância e os } \\
\text { benefícios da } \\
\text { construção } \\
\text { sustentável }\end{array}$ & & \\
\hline
\end{tabular}

Quadro 4: Estratégias para a indústria da construção civil no Estado do Ceará Fonte: Elaborado pelos autores (2016) 


\section{CONSIDERAÇÕES FINAIS}

As variáveis direcionaram-se em maior número para dois cenários, o otimista e o realista; o cenário pessimista teve poucas variáveis. Prospectam-se, ainda, dois cenários favoráveis com boas oportunidades e grandes probabilidades de ocorrência. Quanto ao cenário otimista, vislumbra-se uma situação favorável para o setor, mas é preciso explorar mais as questões do desenvolvimento sustentável. Para o cenário realista, percebe-se que as variáveis também são direcionadas para as questões ambientais, mudanças de comportamento e desenvolvimento de variáveis para a construção sustentável. No caso do cenário pessimista, nota-se que as variáveis são desfavoráveis à empresa, mas podem ser alteradas por ações postas em prática no presente. São variáveis que não estão sob o controle dos empresários, mas que influenciam diretamente os resultados da indústria.

Foram elaboradas 17 estratégias com base nos três cenários prospectados e com os princípios de CSV de Porter e Kramer (2011). As estratégias são de cunho socialmente responsável, sustentável e empresarial, e buscou-se contribuir com ações norteadoras para consolidação de uma construção sustentável.

Concluindo, considerando-se o período (2016-2025), possivelmente a indústria da construção civil no estado do Ceará aumente os investimentos em construções sustentáveis. Assim, com base na probabilidade e favorabilidade das variáveis do cenário otimista e realista, os gestores desta indústria já percebem a importância e os possíveis benefícios da construção sustentável. Entretanto, ainda existe a questão cultural da construção tradicional e a ideia de que a construção sustentável requer grandes investimentos. Algumas mudanças podem ser realizadas com menos recursos financeiros e uma saída estratégica para o aumento da construção sustentável são os incentivos econômicos, como baixas taxas de financiamentos e redução das taxas. A indústria da construção precisa dar importância à questão ambiental. Uma das maneiras para o crescimento do setor pode ser a redução do uso de recursos naturais, minimizando os impactos provocados ao meio ambiente; a criação de valor com a sociedade também é uma alternativa; e incluir a sociedade nos objetivos estratégicos 
da empresa deve ser considerada uma oportunidade. A busca pela construção sustentável no estado do Ceará conduzirá a níveis de equilíbrio econômico, tecnológico, ambiental e social. Para tanto, é necessária a criação de um cluster, assim como de uma política industrial ativa com enfoque na inovação e incorporação tecnológica na produção e na inserção da criação de valor da empresa com a sociedade para a maximização dos resultados de negócios e resultados sociais.

Pode-se considerar como limitação deste estudo a quantidade de 22 empresas que fizeram parte da pesquisa. Assim, sugerem-se para futuras pesquisas a prospecção de cenários em um maior número de empresas da indústria da construção civil no estado do Ceará, a comparação entre estados e regiões brasileiras e, ainda, a elaboração de um índice de CSV. 


\section{REFERÊNCIAS}

Barney, J. B., \& Hesterly, W. S. (2007). Administração estratégica e vantagem competitiva. São Paulo: Pearson Prentice Hall.

Bardin, L. (2009). Análise de conteúdo. Lisboa: Edições 70.

Bezold, C. (2010). Lessons from using scenarios for strategic foresight. Technological Forecasting \& Social Change, 77(9), 1513-1518.

Blanning, R. W., \& Reinig, B. A. (1998). Building scenarios for Hong Kong using EMS. Long Rang Planning, 31(6), 900-910.

Bockstette, V., \& Stamp, M. (2011). Creating shared value: a how-to guide for new corporate evolution. Recuperado em 14 de abril, 2015, de http://www.fsg.org/publications/creating-shared-value-how-guide-newcorporate-revolution\# download-are.

Conselho Brasileiro de Construção Sustentável - CBCS. (2014, novembro). Aspectos da construção sustentável no Brasil e promoção de políticas públicas: subsídios para a promoção da construção civil sustentável (1). Brasília: Ministério do Meio Ambiente.

Câmara Brasileira da Indústria da Construção - CBIC. (2015). Desenvolvimento com sustentabilidade. Câmara Brasileira da Indústria da Construção. Recuperado em 18 de janeiro, 2016, de http: www.cbic.com.br

Confederação Nacional da Indústria - CNI. (2012). Construção verde: desenvolvimento com sustentabilidade. Brasília: CNI.

Coates, J., Durance, P., \& Godet, M. (2010). Strategic foresight issue: introduction. Technological Forecasting \& Social Change, 77(9), 14231425.

Collis, I., \& Hussey, R. (2005). Pesquisa em administração. Porto Alegre: Bookman.

Cooper, D. R., \& Schindler, P. S. (2008). Métodos de pesquisa em administração (7a ed.). Porto Alegre: Bookman.

Crane, A., Palazzo, G., Spence, L. J., \& Matten, D. (2014). Contesting the value of creating shared value. California Management Review, 56(2), 130-153.

Crivits, M., Paredis, E., Boulanger, P. M., Mutombo, E. J. K., Bauler, T., \& Lefin, A.-L. (2010, December). Scenarios based on sustainability discourses: constructing alternative consumption and consumer perspectives. Futures, 42(10), 1187-1199.

Demo, P. (2000). Metodologia do conhecimento científico. São Paulo: Atlas. 
Destatte, P. (2010). Foresight: a major tool in tackling sustainable development. Technological Forecasting \& Social Change, 77(9), 15751587.

Godet, M. (2010). Future memories. Technological Forecasting \& Social Change, 77(9), 1457-1463.

Godet, M.. (1993). Manual de prospectiva estratégica: da antecipação à ação (J. Freitas e Silva Trad.). Lisboa: Dom Quixote.

Homrich, a. S.; de carvalho, m. M.; laurindo, f. J. B. Sustentabilidade e backcasting: a abordagem participativa na criação de valor compartilhado- uma contribuição bibliométrica-simpep 2014. Gestão e saúde, v. 1, n. 1, p. Pag. 1087-1103, 2015.

Husted, B. W., Allen, D. B., \& Kock, N. (2012). Value creation through social strategy. Business \& Society, 54(2), 147-186.

Larson, R., \& Farber, B. (2010). Estatística aplicada (4a ed.). São Paulo: Pearson Prentice Hall.

Marcial, E. C., \& Grumbach, R. J. S. (2006). Cenários prospectivos: como construir um futuro melhor (4a ed.). Rio de Janeiro: FGV.

Malhotra, N. K., Rocha, M. C., Altheman, E., \& Borges, F.M. (2005). Introdução à pesquisa de marketing. São Paulo: Pearson Prentice Hall.

Marinotti, M. (2000). Categorização: agrupando comportamentos ou eventos em classes. Texto elaborado para uso interno na disciplina observação como fonte de dados na análise do comportamento do Programa de Pós-graduação em Psicologia Experimental: Análise do Comportamento da Pontifícia Universidade Católica de São Paulo.

Mello, L. C. B. B., \& Amorim, S. R. L. (2009, maio/ago.). O subsetor de edificações da construção civil no Brasil: uma análise comparativa em relação à União Europeia e aos Estados Unidos. Produção, 19(2), 388399.

Morais Neto, S. de. (2013). Criação de valor compartilhado: um estudo de caso na empresa WEG S.A. Dissertação de Mestrado, Universidade Federal de Santa Catarina: Florianópolis, SC, Brasil.

Oliveira, O. V., \& Forte, S. H. A. C. (2009). A indústria bancária brasileira: construindo cenários prospectivos e identificando as estratégias de utilização mais provável. Revista Portuguesa e Brasileira de Gestão, 8(2), 64-77.

Pfitzer, M., Bockstette, V., \& Stamp, M. (2013, September). Innovating for shared value. Harvard Business Review, 100-107. Recuperado em 10 de junho, 2016, de https://hbr.org/2013/09/innovating-for-shared-value.

Porter, M. E. (1986). Estratégia competitiva: técnicas para análise de indústrias e da concorrência (7a ed.). Rio de Janeiro: Campus. 
Porter, M. E., \& Kramer, M. R. (2011). The big idea: creating shared value. Harvard Business Review, 84(12), 78-92.

Porter, M. E., Hills, G., Pfitzer, M., Patscheke, S., \& Hawkins, E. (2011). Measuring shared value: how to unlock value by linking social and business results. Recuperado em 14 de agosto, 2015, de http:// www.fsg.org.

Schwartz, B. (2000). Self determination: The tyranny of freedom. American Psychologist, 55, 79-88.Schwartz (2000)

Silverman, D. (2009). Interpretação de dados qualitativos: métodos para análise de entrevistas, textos e interações. Porto Alegre: Artmed / Bookman.

Wright, P., Mark, J. K., \& Parnell, J. (2000). Administração estratégica: conceitos. São Paulo: Atlas. 